\title{
Perceived barriers and facilitators to uptake of non-traditional roles by pharmacists in Saudi Arabia and implications for COVID-19 pandemic and beyond: a qualitative study using Theoretical Domain Framework
}

\author{
Eeman Mohammed ${ }^{1}$, Saval Khanal ${ }^{2}$, Zahraa Jalal', Ejaz Cheema' ${ }^{1}$, Mohammed H. Abutaleb³ $^{3}$
} and Vibhu Paudyal ${ }^{1 *}$ (1)

\begin{abstract}
Background: The COVID-19 pandemic has further strengthened the need for pharmacists to uptake non-traditional roles. Pharmacy practice in Saudi Arabia is emerging in recent years with greater policy emphasis on pharmacists taking new clinical roles. This study aimed to explore the experiences, perceptions and barriers of Saudi pharmacists about their uptake of non-traditional roles using Theoretical Domains Framework (TDF).

Methods: A qualitative semi-structured study using face-to-face or telephone interviews were conducted. Eligible participants included qualified pharmacists from Saudi Arabia. Interviews focused on pharmacist's perceptions, current opportunities and key challenges towards the uptake of non-traditional roles. Interviews were audiotaped and transcribed verbatim. Results were analysed through the framework analysis method and were later mapped with respective domains of TDF.

Results: A total of 14 pharmacists completed the interview ( 9 females and 5 males). Participants showed an overall positive attitude towards the uptake of non-traditional roles. Participants felt that there was wider support available for pharmacists at the policy level to uptake non-traditional roles. However, a need for greater recognition of roles by other healthcare professionals and patients were identified. Participants alluded to reluctance of some physicians to take on board the suggestions from a pharmacist. Key barriers to uptake of non-traditional roles were related to environmental context and resources domain of TDF. For example, participants discussed the need for even further practical experiences during their undergraduate degree to become ready to adopt non-traditional roles in clinical practice. Conclusions: Participants of this theoretically informed qualitative study showed an overall positive attitude towards the way pharmacy practice is progressing in Saudi Arabia and their uptake of non-traditional roles. However, there is a need to improve interdisciplinary working, patient awareness of pharmacist competencies and their educational
\end{abstract}

\footnotetext{
*Correspondence: v.paudyal@bham.ac.uk

1 School of Pharmacy, Institute of Clinical Sciences, College of Medical

and Dental Sciences, Sir Robert Aitken Institute for Medical Research,

University of Birmingham, Birmingham B15 2TT, UK

Full list of author information is available at the end of the article
} permits use, sharing, adaptation, distribution and reproduction in any medium or format, as long as you give appropriate credit to the original author(s) and the source, provide a link to the Creative Commons licence, and indicate if changes were made. The images or other third party material in this article are included in the article's Creative Commons licence, unless indicated otherwise in a credit line to the material. If material is not included in the article's Creative Commons licence and your intended use is not permitted by statutory regulation or exceeds the permitted use, you will need to obtain permission directly from the copyright holder. To view a copy of this licence, visit http://creativecommons.org/licenses/by/4.0/. The Creative Commons Public Domain Dedication waiver (http://creativeco mmons.org/publicdomain/zero/1.0/) applies to the data made available in this article, unless otherwise stated in a credit line to the data. 
preparedness in furthering their uptake of non-traditional roles. Addressing such barriers and promoting uptake of novel roles by pharmacists is imperative in the context of emerging COVID-19 and future pandemics.

Keywords: Non-traditional roles, Saudi Arabia, Clinical, Pharmacist, Theoretical domains framework (TDF)

\section{Introduction}

The COVID-19 pandemic has further strengthened the need for pharmacists to uptake non-traditional roles. The healthcare system in Saudi Arabia has aimed to evolve significantly over the last few decades brought by considerable changes in the quality of health and social care services including pharmacy services. With the growing population and increase in life expectancy, the Ministry of Health $(\mathrm{MOH})$ continues to look for new ways to develop the healthcare system that is well suited to meet the current and future needs of Saudi population. In the late 2016, the $\mathrm{MOH}$ provided over 40 health care initiatives as part of the Saudi Vision 2030. Of these 40 initiatives, 15 were related to the advancement of pharmacy practice and pharmaceutical care [1].

Currently, community pharmacy in Saudi Arabia has the largest workforce of pharmacists [2]. Pharmacists working in the community sector are primarily responsible for dispensing and provision of counselling to patients on both prescription and over-the-counter (OTC) medicines [2]. Hospital pharmacy on the other hand offers diverse opportunities for pharmacists in Saudi Arabia that extends beyond dispensing and preparing medications to ensuring safe and effective use of medicines through provision of patient counselling and drug therapy monitoring [3]. Pharmacy graduates may also choose to work in other health care sectors in either public services run by the government or in private sectors such as the university affiliated hospitals, medical services in security or military affairs, and private medical institutions. Other regulatory organisation such as the Saudi Drug and Food Authority, the Saudi Center for Disease Prevention and Control can also be work place for Saudi pharmacists [4].

Pharmacy practice in Saudi Arabia is advancing with the role of pharmacists becoming more patient-centred and clinically focused as shown with the introduction of PharmD programme in Saudi Arabia in 2005 [4]. The curriculum of the PharmD programme in Saudi universities is mainly based on American PharmD curriculum through a collaborative agreement with an Accreditation Council for Pharmacy Education (ACPE) accredited programme, with limited modifications aimed to reflect the culture, and pharmacy administration and law. The aim of this movement was to produce competent pharmaceutical care providers to provide an integrated course to help students develop necessary skills to practise patient-orientated and clinical roles that is in line with the Saudi 2030 vision initiatives set out by the $\mathrm{MOH}$ [5]. Such programme utilised different learning methods such as team- based learning (TBL), problembased learning (PBL), or active learning to help students develop their clinical skills and knowledge in order to be easily accommodated by the healthcare system [6].

The introduction of new curricula in pharmacy schools has shifted the focus of pharmacists from the traditional roles of medicines' compounding and distribution towards patient-centred clinical roles. However, the extent to which these roles have been implemented in Saudi Arabia is unknown. Previous research conducted in Saudi Arabia have demonstrated that pharmacists have the potential to improve patient health outcomes directly in hospital and community settings and indirectly through pharmaceutical industry and practicebased research [7-20]. However, to authors' knowledge, no study to date has been conducted that has explored the pharmacists' perception about the extended roles in pharmacy in Saudi Arabia. In addition there is a lack of theory based research in identifying key barriers and facilitators to uptake of non-traditional roles. This study therefore aims to explore the perceptions of Saudi pharmacists about the uptake of non-traditional roles in pharmacy using Theoretical Domains Framework (TDF). The TDF includes 14 domains covering 84 theoretical constructs [21]. The 14 domains include knowledge, skills, resources, social influences and intentions. TDF enables the identification of appropriate components of planned behavioural interventions, the barriers and enablers which need to be addressed, and the way behaviour changes brought through the interventions can be measured and understood [22-26]. TDF has been recently extensively used in pharmacy practice research [27-29] including their perceptions about extended clinical pharmacy services [30].

\section{Method}

This is a qualitative study conducted with the Saudi pharmacists to identify the perceived barriers and enablers to update the non-traditional role in their country. Eligible participants were recruited using convenience sample of qualified Saudi pharmacists who were in the UK as part of their further study. This cohort was purposively selected as these group of pharmacists were considered to know non-traditional 
roles of pharmacists in other countries (i.e. UK) and the current status of pharmacy practice in their country. Participants were recruited through circulation of invitations to participate in postgraduate forum of a pharmacy higher education institution and snowball sampling technique. An in-depth semi-structured faceto-face or telephone interviews lasting approximately $30 \mathrm{~min}$ were conducted. An interview guide comprising of 18 questions was developed by the members of the research team (Table 1). The interview guide was piloted among four final year MPharm students at the University of Birmingham to determine the clarity, ease of understanding of questions and interview duration.
Participants who gave their consent to take part in the study were interviewed and audio recorded. The audio recordings were transcribed verbatim. The interview was conducted by in English language.

Data analysis for the transcribed data was done through the framework analysis method by using the inductive approach to identify new themes and by deductive approach to identify themes that may have been pre-conceptualised based on previous literature [31]. Subsequently, identified themes were triangulated with the domains in Theoretical Domain Framework (Table 2) [21]. Two researchers independently assessed the domains involved with the themes, and discrepancies were solved by mutual agreement.

Table 1 Interview schedule

\begin{tabular}{|c|c|c|}
\hline S.N. & Questions & Any prompts/ follow up questions \\
\hline 1 & $\begin{array}{l}\text { Can I get you to just briefly describe your area of expertise and how } \\
\text { long you have been qualified for? }\end{array}$ & \\
\hline 2 & $\begin{array}{l}\text { What areas can pharmacists in Saudi Arabia specialise into/what routes } \\
\text { can they take? }\end{array}$ & \\
\hline 3 & What do you think patients expect from pharmacists in Saudi Arabia? & \\
\hline 4 & $\begin{array}{l}\text { If I asked you to define the current role of a pharmacist, what would } \\
\text { you say? }\end{array}$ & Prompt: How does this compares with the roles about a decade ago) \\
\hline 5 & $\begin{array}{l}\text { Can you give me your definition of 'traditional' and non-traditional roles } \\
\text { in pharmacy practice? }\end{array}$ & \\
\hline 6 & $\begin{array}{l}\text { Can you give me an example of a service that you would consider } \\
\text { non-traditional? }\end{array}$ & $\begin{array}{l}\text { Prompt: what other services do pharmacists provide other than } \\
\text { dispensing prescriptions (i.e. vaccinations, OTC counselling, private } \\
\text { counselling, blood pressure monitoring etc.) }\end{array}$ \\
\hline 7 & $\begin{array}{l}\text { How do you feel about how pharmacy practice is changing in Saudi } \\
\text { Arabia? }\end{array}$ & \\
\hline 8 & $\begin{array}{l}\text { Do you that think that the roles of pharmacists is becoming more } \\
\text { clinical? }\end{array}$ & Follow up: How do you feel this has benefited patients? \\
\hline 9 & $\begin{array}{l}\text { Do you think pharmacy education in Saudi Arabia is fit for purpose to } \\
\text { enable new graduates to uptake non-traditional roles? }\end{array}$ & \\
\hline 10 & $\begin{array}{l}\text { Do pharmacists have adequate continuous professional development } \\
\text { opportunities to uptake non-traditional roles? }\end{array}$ & \\
\hline 11 & $\begin{array}{l}\text { How do pharmacists feel about the wider support to uptake non- } \\
\text { traditional roles? }\end{array}$ & Prompt: support from government, employers, patient perceptions etc \\
\hline 12 & Do you feel patients value pharmacists uptaking non-traditional roles? & \\
\hline 13 & $\begin{array}{l}\text { What are your perceptions of a pharmacists' role in the healthcare team } \\
\text { (a multi-disciplinary team of health and social care professionals who } \\
\text { are the first point of contact for patients)? }\end{array}$ & \\
\hline 14 & $\begin{array}{l}\text { How do you think pharmacists work with other healthcare profession- } \\
\text { als? }\end{array}$ & \\
\hline 15 & How is this changing with the uptake of non-traditional roles? & \\
\hline 16 & $\begin{array}{l}\text { Can you tell me about a new and innovative service that you have } \\
\text { provided in recently in your field? }\end{array}$ & \\
\hline 17 & $\begin{array}{l}\text { Can you tell me what you think are the key barriers to the uptake of } \\
\text { non-traditional roles? }\end{array}$ & \\
\hline 18 & $\begin{array}{l}\text { What do you think are the key challenges towards the provision of } \\
\text { non-traditional services pharmacy roles in Saudi Arabia? }\end{array}$ & \\
\hline 19 & Do you have any comments to add? & \\
\hline
\end{tabular}


Table 2 Theoretical Domain Framework

\begin{tabular}{|c|c|}
\hline TDF Domain & Definition \\
\hline Knowledge & An awareness of existence of something \\
\hline Skills & An ability or proficiency acquired through practice \\
\hline Social/professional role and identity & A coherent set of behaviors and displayed personal qualities of an individual in a social or work setting \\
\hline Belief about capabilities & $\begin{array}{l}\text { Acceptance of the truth, reality, or validity about an ability, talent, or facility that a person can put into } \\
\text { constructive use }\end{array}$ \\
\hline Optimism & The confidence that things will happen for the best or that desired goals will be obtained \\
\hline Belief about consequences & Acceptance of truth, reality or validity about outcomes of behavior in a given situation \\
\hline Reinforcement & $\begin{array}{l}\text { Increasing the probability of a response by arranging a dependent relationship, or contingency, between } \\
\text { the response and given stimuli }\end{array}$ \\
\hline Intentions & A conscious decision to perform a behavior or a resolve to act in a certain way \\
\hline Goals & Mental representations of outcomes or end states that an individual wants to achieve \\
\hline Memory, attention and decision processes & $\begin{array}{l}\text { The ability to retain information, focus selectively on aspects of environment, and choose between two or } \\
\text { more alternatives }\end{array}$ \\
\hline Environmental context and resources & $\begin{array}{l}\text { Any circumstance of a person's situation or environment that discourages or encourages the development } \\
\text { of skills and abilities, independence, social competence, and adaptive behavior }\end{array}$ \\
\hline Social influences & Those interpersonal processes that can cause individuals to change their thoughts, feelings, or behavior \\
\hline Emotions & $\begin{array}{l}\text { A complex reaction pattern, involving experiential, behavioral and physiological elements by which the } \\
\text { individual attempts to deal with a personally significant matter or event }\end{array}$ \\
\hline Behavioral regulation & Anything aimed at managing or changing objectively observed or measured actions \\
\hline
\end{tabular}

Adapted from [19]

\section{Results}

\section{Demographic characteristics}

Fourteen participants ( 9 female and 5 male) were included in the study (age range 23-39 years). The included participants practiced in a diverse range of settings with majority working as hospital pharmacists, further information of about demography of the participants is in Table 3.

\section{Key themes and summary of the findings}

Altogether, we identified 16 key themes and subdivided them into 26 subthemes. The identified themes are presented in Table 4 . The Table 4 provides a summary of the key themes and sub-themes, classed as facilitators and barriers. The TDF domains associated with each themes are also presented in Table 4. From the analyses, we found that most of the themes $(n=21 / 26)$ were associated with

Table 3 Demographic profile of the participants

\begin{tabular}{|c|c|c|c|}
\hline SN & Gender & Current practice setting and/or job title & $\begin{array}{l}\text { Length } \\
\text { of pharmacy } \\
\text { practice }\end{array}$ \\
\hline 1 & Female & Academia & $3-4$ years \\
\hline 2 & Male & Academia & 5 years \\
\hline 3 & Male & Academia & 7 years \\
\hline 4 & Female & Academia & 8 years \\
\hline 5 & Female & Academia & 6 months \\
\hline 6 & Female & Hospital pharmacist & 6 years \\
\hline 7 & Female & Hospital pharmacist & 2 years \\
\hline 8 & Male & Primary care & 8 years \\
\hline 9 & Female & Military hospital pharmacist & 7 years \\
\hline 10 & Female & Hospital pharmacist & 3 years \\
\hline 11 & Female & IV pharmacist & 7 years \\
\hline 12 & Female & Clinical trials pharmacist, Saudi FDA & 2 years \\
\hline 13 & Male & Senior pharmacist, Saudi FDA & 10 years \\
\hline 14 & Male & Senior hospital pharmacist, Security forces hospital & 13 years \\
\hline
\end{tabular}




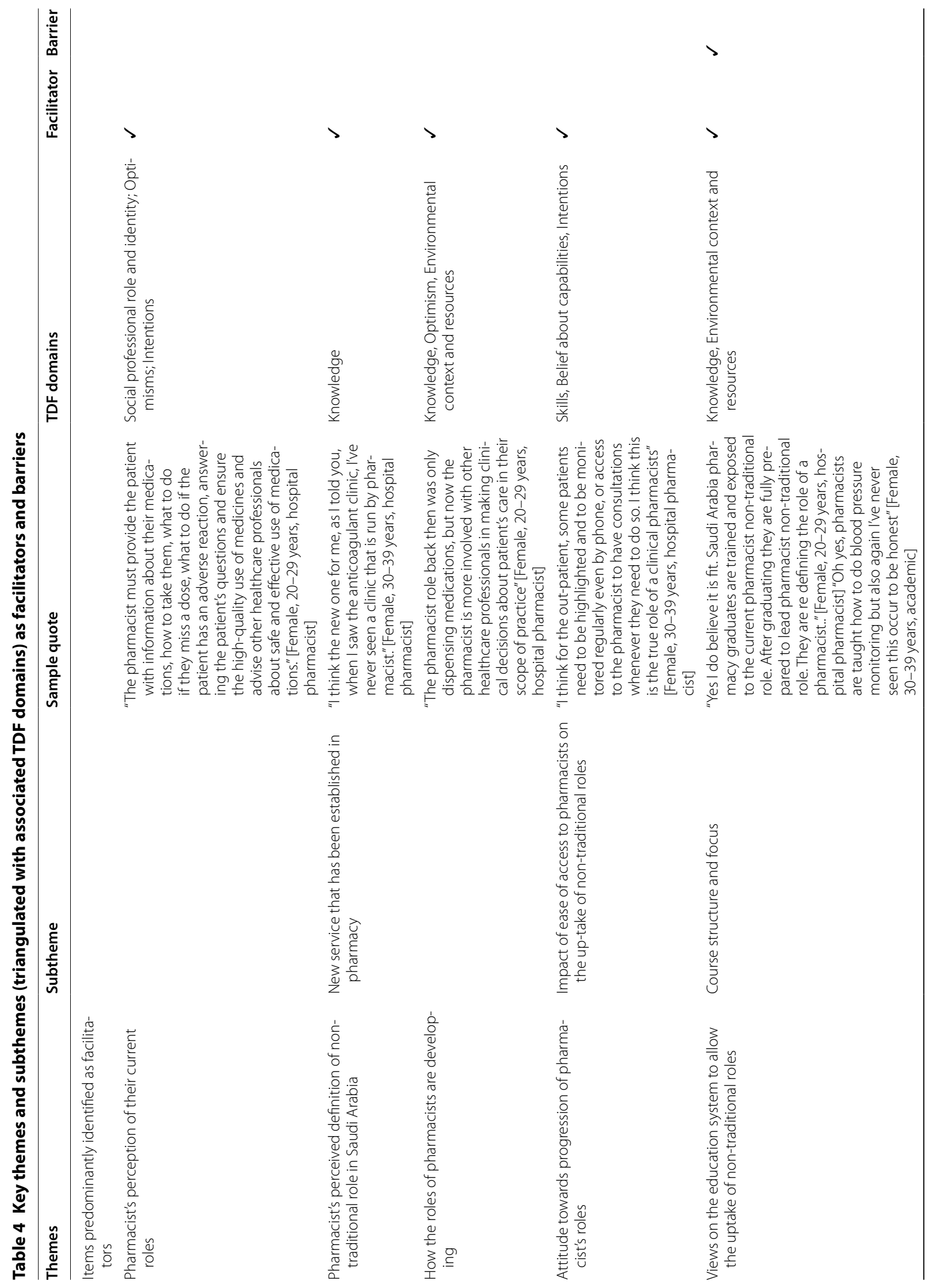




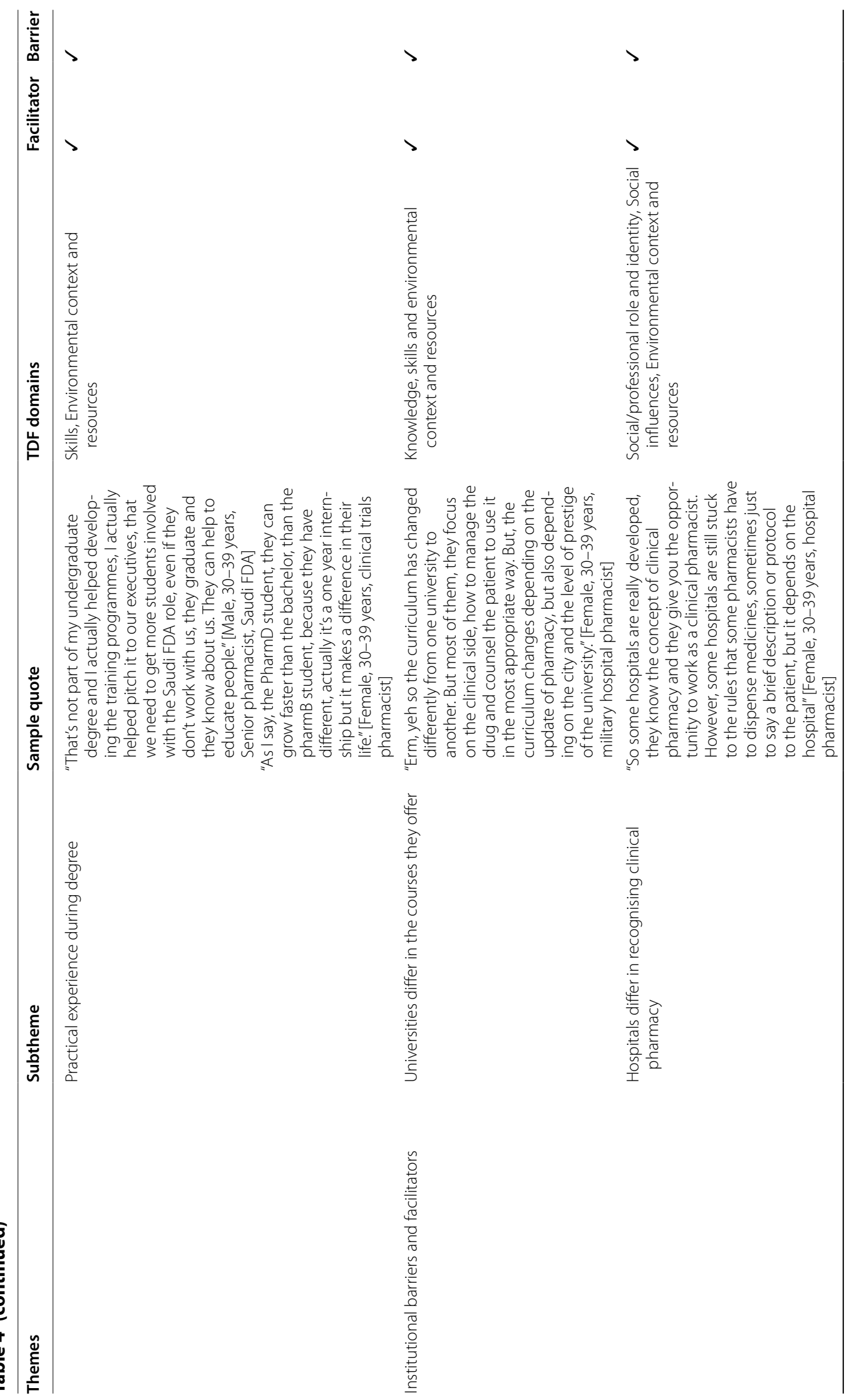




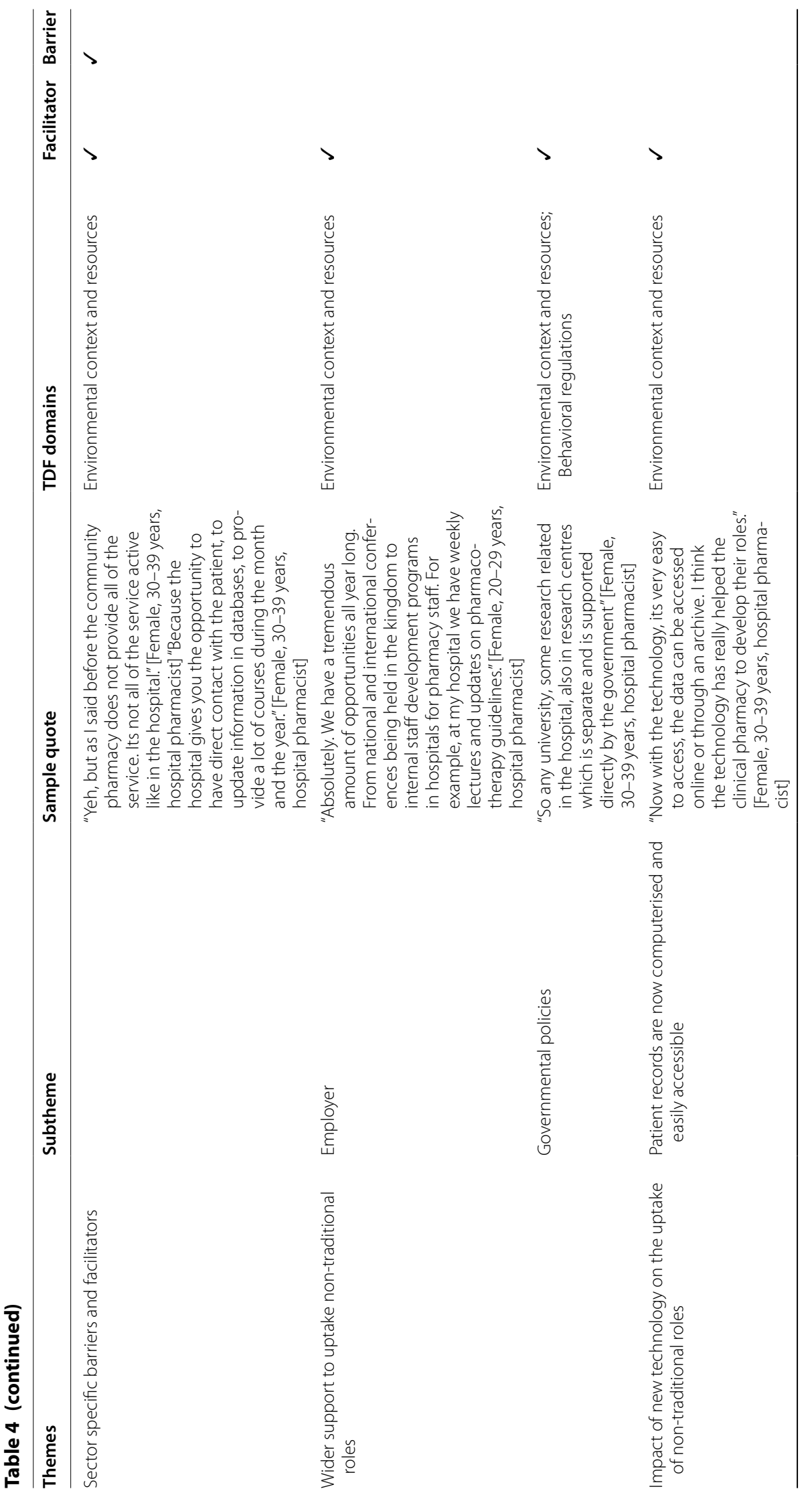




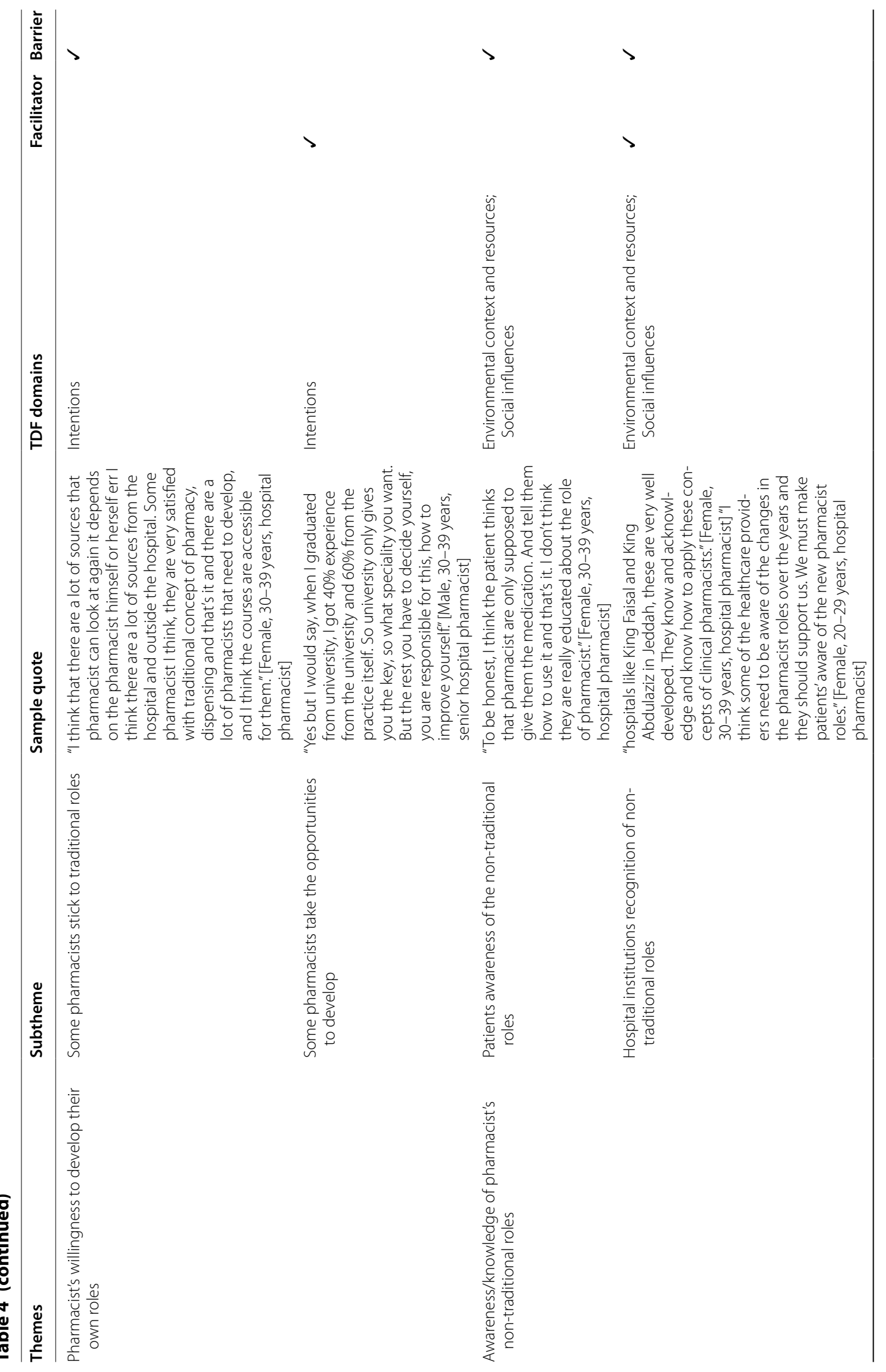




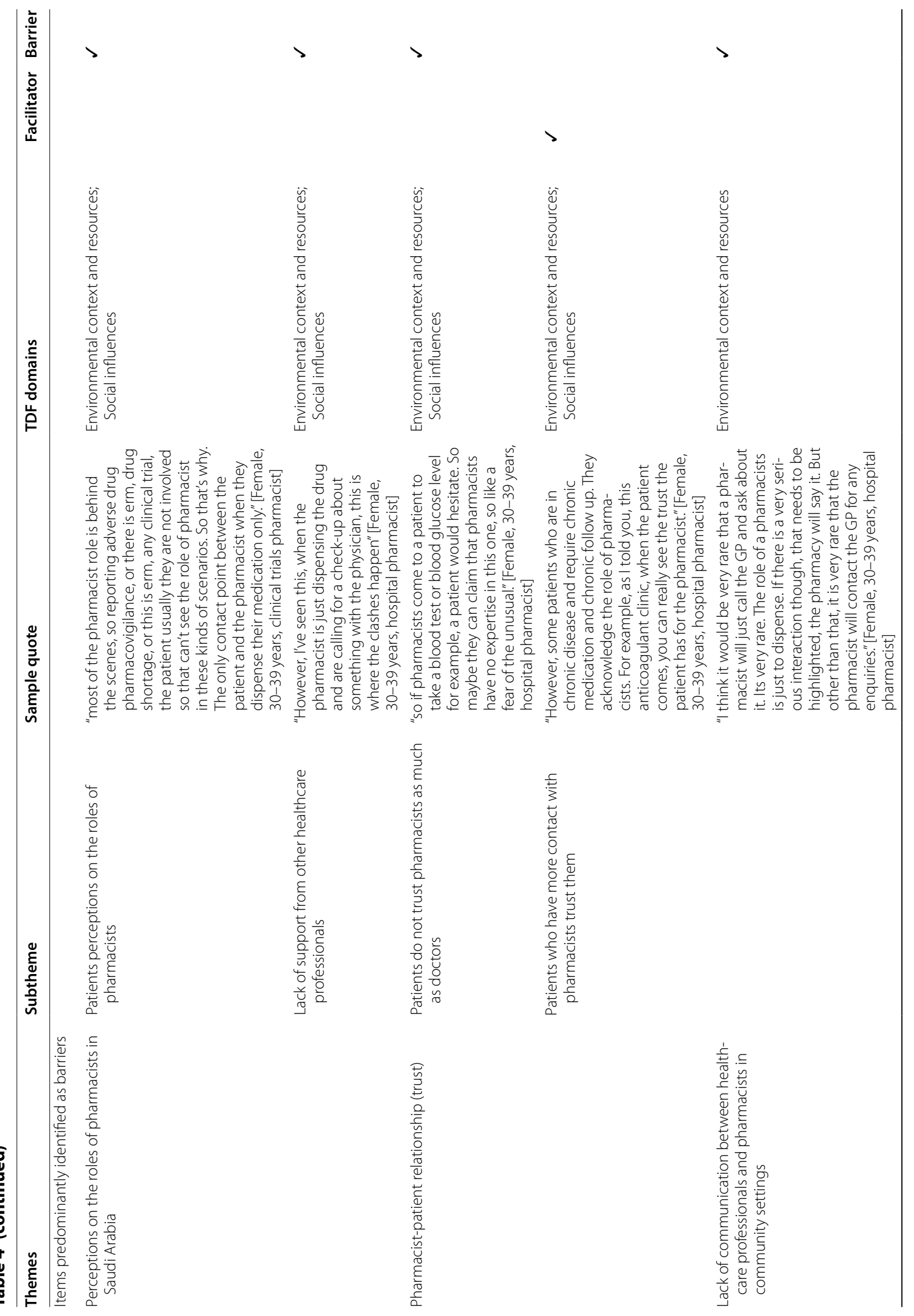




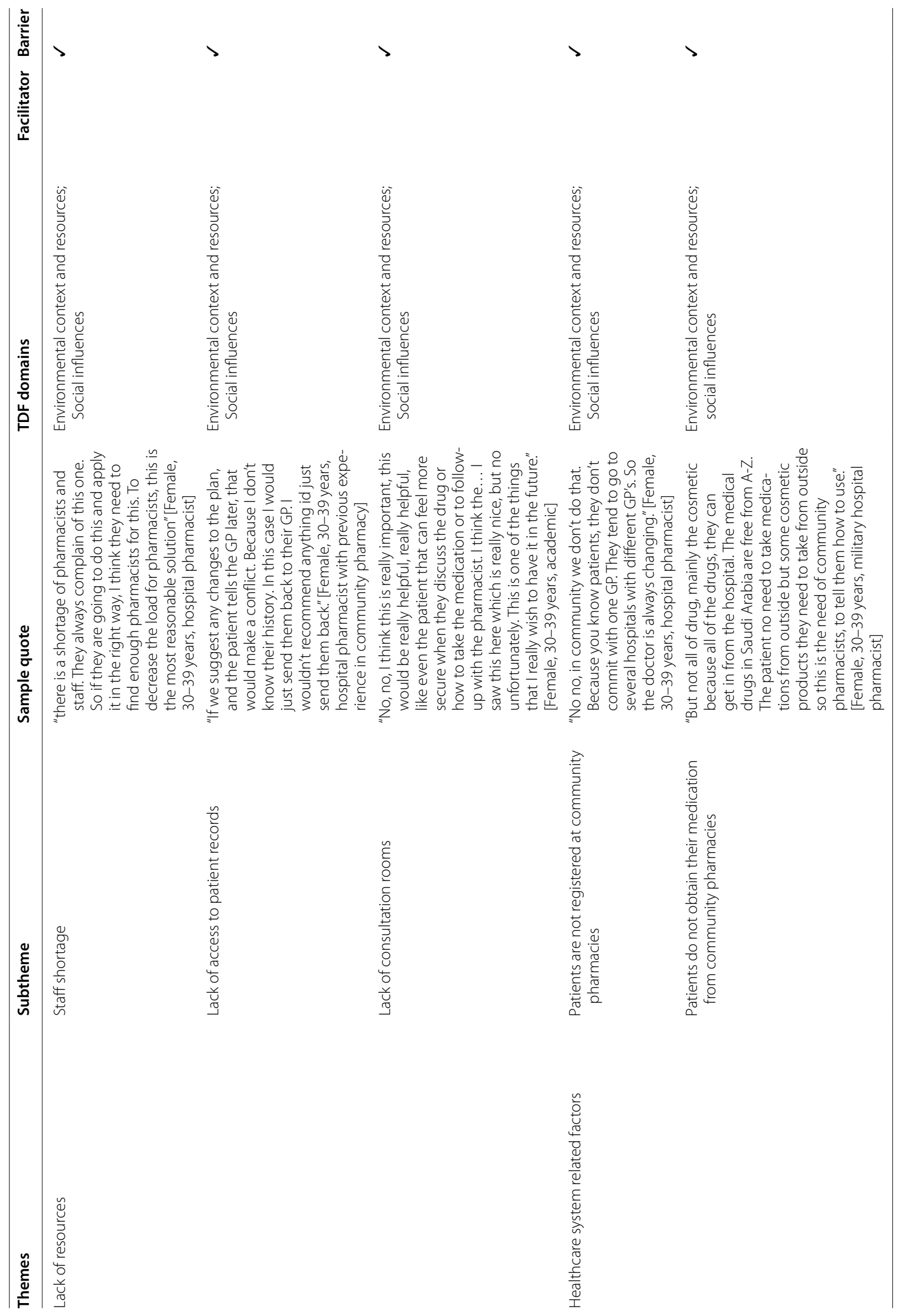


Environmental context and resources domain of the TDF. The subsequent sections of this manuscript describe analyses of each important key themes separately.

\section{How the roles of pharmacists are developing?}

Participants were able to discuss the developing roles and responsibilities of a pharmacists moving away from dispensing and manufacturing roles and made comparisons between current pharmacy practice and pharmacy practice $10-20$ years ago.

"Worth to say on the hospital level that they have a better heard voice in the hospital meetings and committees which is great progress as years ago it was only related to the physicians." [Female, 30-39 years, IV pharmacist].

The change in the pharmaceutical sector was highlighted as a major development and advancement for Saudi Arabia providing pharmacist with the opportunity to work in large pharmaceutical companies and move away from the traditional compounding and manufacturing role to researching and developing drug molecules.

...manufacturing role to researching and developing drug molecules: "Erm, actually there are local companies that have been around for more than 20 years but most of the local companies, they did not develop the molecular, they just take it as a powder and prepare it as a different form. But now, the local companies are supported by the government to develop from a small molecule into a drug..." [Female, 30-39 years, military hospital pharmacist].

\section{Views on the education system to allow the uptake of non-traditional roles}

The education system was discussed by participants as an important factor to the development of pharmacists' roles and providing them with the necessary knowledge and skills to carry out clinical roles. Participants were asked whether the modules taught to undergraduate pharmacy students was fit for purpose to allow pharmacists to uptake non-traditional roles.

"Yes I do believe it is fit. Saudi Arabia pharmacy graduates are trained and exposed to the current pharmacist non-traditional role. After graduating they are fully prepared to lead pharmacist nontraditional role. They are re defining the role of a pharmacist.." [Female, 20- 29 years, hospital pharmacist].

Practical experience and placements throughout the undergraduate years were also identified by participants as a facilitator of the uptake of non-traditional roles as it allowed students to become exposed to real life pharmacy practice and aid in breaking the perception of students that pharmacists' do not take on roles beyond dispensing.

"As I say, the PharmD student, they can grow faster than the bachelor, than the BPharm student, because they have different, actually it's a one year internship but it makes a difference in their life." [Female, 30-39 years, clinical trials pharmacist].

One participant practicing as a senior pharmacist and active member of the pharmaceutical products approval committee felt that students were not gaining practical experience in the Saudi FDA.

"That's not part of my undergraduate degree and I actually helped developing the training programmes, I actually helped pitch it to our executives that we need to get more students involved with the Saudi FDA role, even if they don't work with us, they graduate and they know about us. They can help to educate people." [Male, 30-39 years, Senior pharmacist, Saudi FDA].

\section{Wider support to uptake non-traditional roles}

Participants felt that there was wider support for pharmacists to uptake non-traditional roles, offering continuous professional development opportunities such as training courses and residency programmes.
"Absolutely. We have a tremendous amount of opportunities all year long. From national and international conferences being held in the kingdom to internal staff development programs in hospitals for pharmacy staff. For example, at my hospital we have weekly lectures and updates on pharmaco- therapy guidelines." [Female, 20-29 years, hospital pharmacist].

Wider support from the government was a sub-theme identified from the transcripts. Participants felt that the government encouraged them to uptake non-traditional roles particularly through initiatives of Saudi Vision 2030.

"Recently, there a lot of things changing. The first one is to push all young people to work as a manager, as a leader, which is good. Prince Mohammed Bin Salman, he is pushing all of the young people, really supporting them from A-Z." [Female, 30-39 years, military hospital pharmacist]. 
However, one participant, a clinical trials pharmacist described that there was generally a lack of recognition of some of the roles such as involvement in research or regulatory affairs.

"but until now they don't erm, they don't classify, or they don't consider any other non-traditional career paths like research, like pharmacists involved in research or pharmacoeconomics, or regulatory affair or drug pricing, pharmacovigilance." [Female, 30-39 years, clinical trials pharmacist].

\section{Awareness/knowledge of pharmacist's non-traditional roles}

The importance of the awareness and knowledge of nontraditional roles within pharmacy was identified as key to the application of these roles within different institutions. For example, one participant highlighted that being aware of clinical pharmacy practice was a facilitator to the uptake of non-traditional roles.

"Hospitals like King Faisal [Specialist] and King Abdulaziz [Medical City] in Jeddah, these are very well developed. They know and acknowledge and know how to apply these concepts of clinical pharmacists." [Female, 30-39 years, hospital pharmacist].

However, one participant described a lack of knowledge on clinical roles, particularly by patients.

"To be honest, I think the patient thinks that pharmacists are only supposed to give them the medication. And tell them how to use it and that's it. I don't think they are really educated about the role of pharmacist." [Female, 30-39 years, hospital pharmacist].

\section{Perceptions on the roles of pharmacists in Saudi Arabia}

Patients' perceptions on the roles and what services they expect from pharmacists in Saudi Arabia was identified by all participants. Participants felt that patients were not as comfortable with pharmacists when enquiring about their healthcare as they were with doctors which may be due to lack of awareness on the development of clinical pharmacy practice.

"Until now, a patient expect pharmacist to know every single thing about drugs, even about herbal medication. They even come and ask us whether I can use this herbs instead of this drug or not. So everything people expect from us is knowing about drugs. When it comes to disease or diagnosis, they tend not to listen to us. They prefer to go to the physician or GP." [Female, 30-39 years, hospital pharmacist].
The lack of support from other healthcare professionals due to perceptions and expectations of the roles of pharmacists was another sub-theme identified regarding key challenges towards the uptake of non-traditional roles by pharmacists. Participants paid attention to the fact that many healthcare professionals do not recognise the clinical knowledge of pharmacists and are reluctant to take on board a suggestion from a pharmacist.

"However, I've seen this, when the pharmacist is just dispensing the drug and are calling for a check-up about something with the physician, this is where the clashes happen" [Female, 30-39 years, hospital pharmacist].

However, as highlighted by another participant, this perception was different where a pharmacist was regularly involved in ward rounds and works as part of the multidisciplinary team when reviewing a patient.

"I think this is most of the time when the pharmacist really works on a daily basis and er, are in the wards going with the physician on the daily rotation, I think they will develop a good relationship with them and they work easily." [Female, 30-39 years, hospital pharmacist].

\section{Impact of new technology on the uptake of non-traditional roles}

The increase in the use of technology within healthcare was described by participants as a facilitator to uptake non-traditional roles particularly due to easy access to patient records and prescriptions. This would allow pharmacists to intervene when necessary and take a holistic approach to the treatment of patients.

"Now with the technology, its very easy to access, the data can be accessed online or through an archive. I think the technology has really helped the clinical pharmacy to develop their roles." [Female, 30-39 years, hospital pharmacist].

\section{Pharmacist-patient relationship (trust)}

Participants identified the relationship between the pharmacist and the patient as having a key impact on a pharmacist's ability to carry out non-traditional roles. Participants felt that currently, many patients do not trust the pharmacists due to pharmacists not being able to develop their relationship with them further.

"So patients, they don't accept the interventions done by pharmacists. They say ok, this medication has been prescribed for me from the doctor, and the doctor knows what they are doing, and they feel that the 
doctor knows everything. So they don't accept pharmacists to take a bigger role." [Male, 30-39 years, senior hospital pharmacist].

One participant explained that where a patient is in a chronic condition and is required to meet with the pharmacist often, they begin to develop a strong relationship with them and are recognised by the patient as a key healthcare provider.

"However, some patients who are in chronic disease and require chronic medication and chronic follow up. They acknowledge the role of pharmacists. For example, as I told you, this anticoagulant clinic, when the patient comes, you can really see the trust the patient has for the pharmacist." [Female, 30-39 years, hospital pharmacist].

\section{Discussion}

To authors' knowledge, this is the first qualitative study that has explored the pharmacists' perception about the uptake of non-traditional roles in pharmacy in Saudi Arabia. The findings of this study suggest that there is a clear shift towards the uptake of non-traditional pharmacy roles with participants showing an overall positive attitude towards the way pharmacy practice is progressing in Saudi Arabia.

Participants defined their current roles as pharmacists as being consultants of medicines and were expected to recall all information on a drug. This correlates with the current perceptions of patients about the roles of pharmacists and what services a patient expects pharmacists to provide. Participants were unanimous on their views about patient expectations and believed that patients were not willing to seek advice from community pharmacists on their disease states or general issues regarding their healthcare. Previous research has shown that community pharmacists in Saudi Arabia are often expatriate males [32-34] and therefore there may often be language or cultural barriers to patients advice seeking from pharmacy [35]. The new system of the Ministry of Health Wasfaty and the nationalisation employment program in community pharmacies is aimed to address these barriers $[36,37]$.

Participants attributed the lack of patient engagement to the limited clinical knowledge of community pharmacists. However, participants who stated hospital pharmacy as their current clinical practice setting, reported that their regular patients had a different view on the role of pharmacists and felt that patients perceived them to be an integral member of the multidisciplinary healthcare team. Previous research shows that majority of Saudi pharmacy students showed interest to work in hospitals after graduation [38]. Taking a holistic, patient-centred approach is important to allow patients to recognise pharmacists as healthcare providers [39].

Participants were able to provide examples of nontraditional roles of pharmacists which existed in their respective practice setting. Pharmacists running their own specialised clinics such as anticoagulant and diabetes clinic was amongst the examples of non-traditional roles cited by participants. Other non-traditional roles quoted by participants included pharmacists in health informatics; clinical trials and pharmacists working in specialised ambulatory clinics. Wider support available for pharmacists to uptake non-traditional roles was perceived positively by participants. Hospitals such as King Faisal Specialist Hospital \& Research centre are now offering the PGY-1 and PGY-2 residency programmes to train pharmacists to specialise and become clinical pharmacists in their chosen area of interest [40]. Majority of the participants felt that there was support from the Ministry of Health for pharmacists to carry out continuous professional development. In order to keep professional license valid, every pharmacist has to get not less than 20 CPD credits a year in Saudi Arabia.

Lack of exposure to patients and real-life pharmacy practice experience during pharmacy education was identified as a barrier towards the uptake of non-traditional roles by participants. The introduction of the PharmD's one-year internship, however, was described by participants as a positive change in the education system as it allowed students to experience various clinical pharmacy sectors during their rotations in hospitals.

Participants were asked to identify any major challenges towards the uptake of non-traditional roles by pharmacists in Saudi Arabia. Lack of support and reluctance to acknowledge the pharmacist interventions and suggestions for improving patient healthcare were among some of the challenges highlighted by participants. A previous study that explored the perceptions of physicians about the clinical roles of pharmacist in hospitals in Saudi Arabia reported that only $4 \%$ of the physicians had worked with a clinical pharmacist previously while majority were unclear about the role of a clinical pharmacist [41]. Lack of communication between physicians and pharmacists particularly in community settings was reported by majority of the participants who expressed that pharmacists did not communicate with the doctors in routine unless necessary such as communicating about a serious interaction on the prescription. Communication gaps between healthcare institutions and professionals has been recognised as a contributor towards medication safety problems seen in Saudi Arabia [42]. Lack of consultation rooms, the lack of access to patient care 
records and staff shortages were some of the other challenges that were highlighted by the participants. These findings corroborates with previous studies investigating practice changes in community pharmacy [43-46] and in Saudi Arabia these factors could be related to deficiency of experiential part of training, lack of clinically qualified preceptors, lack of training in advanced settings as were addressed in published studies [47-49]. Participants believed that such barriers limited pharmacists' roles and if addressed, would support the uptake of non-traditional roles as well as improve patient health outcomes. There is a need to raise patient awareness about the non-traditional roles of pharmacists in all practice settings. It may be achieved through provision of patient education about the clinical roles of pharmacists. The successful implementation of the initiatives set out in the new Model of Care as part of Saudi Vision under the Ministry of Health will enhance the efficacy of the current healthcare system and will have a significant impact on the development of community pharmacy practice in Saudi Arabia. Furthermore, increasing the workforce of Saudi pharmacists in community pharmacies will help resolve the issue of staff shortages in community settings.

The expansion of pharmacists' roles and workforce in the community is also imperative on the face of the COVID-19 pandemic and other infectious diseases of concern [50-53]. The pandemic has required pharmacy services to offer extended roles in all sectors including continuation of the provision of routine services in the time of hardships and shortages in medicines supply; uptake of novel roles in primary care, hospital and critical care; participation in clinical trials; and provision of education, medicines information; and offering vaccinations [50]. The findings of this study will be useful in enabling pharmacists' preparedness and response to current and future pandemic in Saudi Arabia and beyond by harnessing the facilitators and addressing barriers to uptake of novel roles as identified in this study.

The use of TDF to the research is a key strength to this study. The domains identified from the TDF analysis can be used to map the appropriate behaviour change techniques (BCTs) using behavioural change wheel ( $\mathrm{BCW}$ to design the appropriate interventions to address the barriers identified in this study [21, 54]. Recruitment through convenience sampling, non-representation of all sectors of practice, and lack of data saturation are key limitations. However, the participants represented experienced practitioners with insight of pharmacy practice in both Saudi Arabia and a Western country with advanced pharmacy practice roles. A larger qualitative study and interventions development incorporating novel roles and their evaluations are needed that can inform policy makers, pharmacy services, researchers, and health systems in Saudi Arabia to further the uptake of non-traditional roles by pharmacists.

\section{Conclusions}

This theoretically informed qualitative study shows that there is a growing interest in pharmacists towards the uptake of non-traditional roles in Saudi Arabia. Pharmacists showed an overall positive attitude towards the way pharmacy practice is progressing in Saudi Arabia. However, there is a need for some interventions especially those aiming to modify environmental context and resources to encourage Saudi pharmacists to update the non-traditional roles. Addressing such barriers and promoting uptake of novel roles by pharmacists is imperative in the context of COVID-19 and future pandemics.

\section{Abbreviations}

MOH: Ministry of Health; OTC: Over-the-counter; TDF: Theoretical Domains Framework; UK: United Kingdom.

\section{Acknowledgements}

None

\section{Authors' contributions}

SK, ZJ, EC and VP designed the study. EE was the study researcher and conducted interviews and analysed the data and produced the first draft of the manuscript. VP was the principal supervisor to EE. MHA contributed to analysis and interpretation of data and provided expert input in relation to Saudi Pharmacy Practice. All authors contributed with substantial comments, editing and revision. All authors read and approved the final manuscript.

\section{Funding}

This study was funded by University of Birmingham.

\section{Availability of data and materials}

All data generated or analysed during this study are included in this published article.

\section{Ethics approval and consent to participate}

The study was approved by the University of Birmingham Ethics Committee (Ref: 58:2018). Informed consent was obtained from each participant prior to their participation in the research.

\section{Consent for publication}

Informed consent was obtained from each participant prior to their participation in the research for their quotes to be used for publication.

\section{Competing interests}

The authors declare that they have no competing interests.

\section{Author details}

1 School of Pharmacy, Institute of Clinical Sciences, College of Medical and Dental Sciences, Sir Robert Aitken Institute for Medical Research, University of Birmingham, Birmingham B15 2TT, UK. ${ }^{2}$ Behavioral Science Group, Warwick Business School, University of Warwick, Coventry, UK. ${ }^{3}$ Pharmacy Department, King Fahad Central Hospital-Jazan Health Affairs, Ministry of Health, Jazan, Saudi Arabia.

Received: 7 December 2020 Accepted: 11 February 2021

Published online: 24 February 2021 


\section{References}

1. Alomi YA. New pharmacy model for vision 2030 in Saudi Arabia. J Pharm Pract and Community Med. 2017:3(3):194-6.

2. AlRuthia Y, Alsenaidy MA, Alrabiah HK, AlMuhaisen A, Alshehri M. The status of licensed pharmacy workforce in Saudi Arabia: a 2030 economic vision perspective. Hum Resour Health. 2018;16(1):28

3. Al-Jedai A, Qaisi S, Al-Meman A. Pharmacy practice and the health care system in Saudi Arabia. Can J Hosp Pharm. 2016;69(3):231-7.

4. Ministry of Health (Saudi Arabia). Statistical year book. 2017. https://www. moh.gov.sa/en/Ministry/Statistics/book/Pages/default.aspx. Accessed 13 Dec 2018.

5. Alkatheri AM, Albekairy AM, Khalidi N, Phelps SJ, Gourley DR, Al Jeraisy M, Qandil AM. Implementation of an ACPE-Accredited PharmD curriculum at a Saudi College of Pharmacy. Am J Pharm Educ. 2019;83(9):6237-6237.

6. Almeman AA. Strategic analysis of clinical pharmacy education in Saudi Arabia. Trop J Pharm Res. 2020;19(6):1303-11.

7. Alaqeel S, Abanmy NO. Counselling practices in community pharmacies in Riyadh, Saudi Arabia: a cross-sectional study. BMC Health Serv Res. 2015;15(1):557.

8. Al-Arifi MN. Patients' perception, views and satisfaction with pharmacists' role as health care provider in community pharmacy setting at Riyadh, Saudi Arabia. Saudi Pharm J. 2012;20(4):323-30.

9. Albekairy AM, Khalidi N, Alkatheri AM, Althiab K, Alharbi S, Aldekhael $S$, et al. Strategic initiatives to maintain pharmaceutical care and clinical pharmacists sufficiency in Saudi Arabia. SAGE Open Med. 2015;3:2050312115594816.

10. Alhamoudi A, Alnattah A. Pharmacy education in Saudi Arabia: the past, the present, and the future. Curr Pharm Teach Learn. 2018;10(1):54-60.

11. Aljadhey $\mathrm{H}$, Asiri Y, Albogami Y, Spratto G, Alshehri M. Pharmacy education in Saudi Arabia: a vision of the future. Saudi Pharm J. 2017:25(1):88-92.

12. Aljadhey $\mathrm{H}$. Experience and future of introductory pharmacy practice training in developing countries: example of Saudi Arabia. Am J Pharm Educ. 2012;76(10):205.

13. Almaghaslah D, Alsayari A, Asiri R, Albugami N. Pharmacy workforce in Saudi Arabia: challenges and opportunities: a cross-sectional study. Int J Health Plann Manag. 2019a;34(1):e583-93.

14. Alsultan MS, Khurshid F, Mayet AY, Al-Jedai AH. Hospital pharmacy practice in Saudi Arabia: dispensing and administration in the Riyadh region. Saudi Pharm J. 2012;20(4):307-15.

15. Alsultan MS, Khurshid F, Salamah HJ, Mayet AY, Al-Jedai AH. Hospital pharmacy practice in Saudi Arabia: prescribing and transcribing in the Riyadh region. Saudi Pharm J. 2012;20(3):203-10.

16. Alsultan MS, Mayet AY, Khurshid F, Al-Jedai AH. Hospital pharmacy practice in Saudi Arabia: drug monitoring and patient education in the Riyadh region. Saudi Pharm J. 2013;21(4):361-70.

17. Asiri YA. Emerging frontiers of pharmacy education in Saudi Arabia: the metamorphosis in the last fifty years. Saudi Pharm J. 2011;19(1):1-8.

18. Saddique AA. Development of Clinical Pharmacy services at King Khalid University Hospital and its impact on the quality of healthcare provided. Saudi Pharm J. 2012;20(3):273-7.

19. Saleh GB, Rezk NL, Laika L, Ali A, El-Metwally A. Pharmacist, the pharmaceutical industry and pharmacy education in Saudi Arabia: a questionnaire-based study. Saudi Pharm J. 2015;23(5):573-80.

20. Sultana K, Al Jeraisy M, Al Ammari M, Patel R, Zaidi ST. Attitude, barriers and facilitators to practice-based research: cross-sectional survey of hospital pharmacists in Saudi Arabia. J Pharm Policy Pract. 2016;9(1):4.

21. Cane J, O'Connor D, Michie S Validation of the theoretical domains framework for use in behaviour change and implementation research. Implement Sci. 2012;7(1):37.

22. Horppu R, Martimo K, MacEachen E, Lallukka T, Viikari-Juntura E. Application of the theoretical domains framework and the behaviour change wheel to understand physicians' behaviors and behavior change in using temporary work modifications for return to work: a qualitative study. J Occup Rehabil. 2018;28(1):135-46.

23. Craig LE, Mclnnes E, Taylor N, Grimley R, Cadilhac DA, Considine J, et al. Identifying the barriers and enablers for a triage, treatment, and transfer clinical intervention to manage acute stroke patients in the emergency department: a systematic review using the theoretical domains framework (TDF). Implement Sci. 2016;11(1):157.
24. Garbutt JM, Dodd S, Walling E, Lee AA, Kulka K, Lobb R. Theory-based development of an implementation intervention to increase HPV vaccination in pediatric primary care practices. Implement Sci. 2018;13(1):45.

25. Stewart D, Paudyal V, Cadogan C, Hazen A, Okuyan B, Lutters M, Henman $M$, Fialova D. A survey of the European Society of Clinical Pharmacy members' research involvement, and associated enablers and barriers. Int J Clin Pharm. 2020:42:1073-87.

26. Bele S, Cassidy C, Curran J, Johnson DW, Saunders C, Bailey JM. Barriers and enablers to implementing a virtual tertiary-regional Telemedicine Rounding and Consultation (TRAC) model of inpatient pediatric care using the Theoretical Domains Framework (TDF) approach: a study protocol. BMC Health Serv Res. 2019;19(1):1-9.

27. Paudyal V, MacLure K, Buchanan C, Wilson L, McLeod J, Stewart D. When you are homeless, you are not thinking about your medication, but your food, shelter or heat for the night': behavioural determinants of the homeless population adherence to prescribed medicines. Public Health. 2017;148:1-8

28. Paudyal V, Maclure K, Forbes-McKay K, McKenzie M, McLeod J, Smith A, Stewart D. If I die, I die, I don't care about my health': perspectives on self-care of people experiencing homelessness. Health Soc Care Comm. 2020;28:160-72.

29. Gunner E, Chandan SK, Marwick S, Saunders K, Burwood S, Yahyouche A, Paudyal V. Provision and accessibility of primary healthcare services for people who are homeless: a qualitative study of patient perspectives in the UK. BJGP. 2019;69(685):e526-36.

30. Paudyal V, Gibson Smith K, MacLure K, Forbes-McKay K, Radley A, Stewart D. Perceived roles and barriers in caring for the people who are homeless: a survey of UK community pharmacists. Int J Clin Pharm. 2019:41(1):215-27.

31. Gale NK, Heath G, Cameron E, Rashid S, Redwood S. Using the framework method for the analysis of qualitative data in multi-disciplinary health research. BMC Med Res Methodol. 2013;13(1):1-8.

32. AlRuthia $Y$, Alsenaidy MA, Alrabiah HK, et al. The status of licensed pharmacy workforce in Saudi Arabia: a 2030 economic vision perspective. Hum Resour Health. 2018;16:28. https://doi.org/10.1186/s1296 0-018-0294-8.

33. Almaghaslah $D$, Alsayari A, Asiri R, Albugami N. Pharmacy workforce in Saudi Arabia: challenges and opportunities: a cross-sectional study. Int J Health Plann Manag. 2019b;34:e583-93. https://doi.org/10.1002/ hpm.2674.

34. Balkhi B, Alghamdi A, Alhossan A, Alhamami A, Asiri YA. Pharmacy students attitude and perception toward working in community pharmacy in Saudi Arabia. Saudi Pharm J. 2020;28(4):397-402.

35. Alfadl AA, Alrasheedy AA, Alhassun MS. Evaluation of medication counseling practice at community pharmacies in Qassim region, Saudi Arabia. Saudi Pharm J. 2018;26(2):258-62.

36. Rasheed MK, Alqasoumi A, Hasan SS, et al. The community pharmacy practice change towards patient-centered care in Saudi Arabia: a qualitative perspective. J Pharm Policy Pract. 2020;13:59. https://doi. org/10.1186/s40545-020-00267-7

37. Al Aloola N, Aljudaib S, Behery F et al. Perception of the community toward transition of pharmaceutical care services from Ministry of Health Primary Healthcare Centers to Community Pharmacies, 15 December 2020, PREPRINT (Version 1) available at Research Square. https://doi. org/https://doi.org/10.21203/rs.3.rs-124402/v1.

38. Bin Saleh $G$, et al. Pharmacist, the pharmaceutical industry and pharmacy education in Saudi Arabia: a questionnaire-based study. Saudi Pharm J. 2015;23(5):573-80

39. Lai E, Trac L, Lovett A. Expanding the pharmacist's role in public health. Univ J Public Health. 2013;1(3):79-85.

40. Tsuyuki RT, Beahm NP, Okada H, Al Hamarneh YN. Pharmacists as accessible primary health care providers: review of the evidence. Can Pharm J. 2018;151(1):2

41. Almazrou S, Alnaim L, Al-Kofide H. Perceptions, expectations and barriers of physicians towards working with clinical pharmacists in Saudi Arabia. J Sci Res Rep. 2015:6:404-15.

42. Aljadhey H, Mahmoud MA, Hassali MA, Alrasheedy A, Alahmad A, Saleem $F$, et al. Challenges to and the future of medication safety in Saudi Arabia: a qualitative study. Saudi Pharm J. 2014;22(4):326-32

43. Paudyal V, Hansford D, Cunningham S, Stewart D. Community pharmacists' adoption of medicines reclassified from prescription only status: a 
systematic review of factors associated with decision making. Pharmacoepid Drug Saf. 2012a;21(4):396-406.

44. Paudyal V, Hansford D, Cunningham S, Stewart D. Pharmacists' perceived integration into practice of over-the-counter simvastatin five years post reclassification. Int J Clin Pharm. 2012b;34(5):733-8.

45. Paudyal V, Hansford D, Cunningham S, Stewart D. Over the counter prescribing and pharmacists' adoption of new medicines: diffusion of innovations. Res Soc Admin Pharm. 2012c;9(3):251-62.

46. Paudyal V, Cunningham S, Gibson Smith K, MacLure K, Ryan C, Cordina M. Methodological considerations in clinical outcomes assessment of pharmacy-based minor ailments management: a systematic review. PLoS ONE. 2018;13(10):e0205087.

47. Ameer L, MacLure K, Tonna A, Stewart D. An initial exploration of the perceptions of preparedness to practise among Saudi Arabian trained hospital pharmacists. Pharm Pract. 2018;16(2):1192.

48. Almetwazi M, Alhammad A, Alhossan A, et al. Pharmacy students'satisfaction with Introductory Pharmacy Practice Experiences (IPPE) at community pharmacy: the case of Saudi Arabia. Saudi Pharm J. 2020;28(1):68-73. https://doi.org/10.1016/j.jsps.2019.11.006.

49. Zeitoun A, Sacre H, Hallit S, et al. Clinical preceptor competencies for a better pharmacy education: a suggested framework for Lebanon. J Pharm Policy Pract. 2020;13:21. https://doi.org/10.1186/s40545-02000217-3.

50. Paudyal V, Cadogan C, Fialova D, Henman M, Hazen A, Okuyan B, Lutters M, Stewart D. Provision of clinical pharmacy services during the COVID-19 pandemic: experiences of pharmacists from 16 European countries. Res Soc Admin Pharm. 2020. https://doi.org/10.1016/j.sapharm.2020.11.017.

51. Ali S, Ur-Rehman T, Ali M, Haque S, Rasheed F, Lougher E, Nawaz MS, Paudyal V. Improving access to the treatment of hepatitis $\mathrm{C}$ in low- and middle-income countries: evaluation of a patient assistance programme. Int J Clin Pharm. 2020. https://doi.org/10.1007/s1 1096-020-01202-1.

52. Ali S, Ur-Rehman T, Lougher E, Mutimer D, Ali M, Paudyal V. Impact of HIV and chronic kidney disease comorbidities on hepatitis $C$ treatment choices, drug-drug interactions and hepatitis C cure. Int J Clin Pharm. 2020;42(2):515-26.

53. Ali S, Ali M, Paudyal V, Rasheed F, Ullah S, Haque S, Ur-Rehman T. A randomized controlled trial to assess the impact of clinical pharmacy interventions on treatment outcomes, health related quality of life and medication adherence among hepatitis $\mathrm{C}$ patients. Patient Prefer Adher 2019;13:2089-100.

54. Michie S, Atkins L, West R. The behaviour change wheel: a guide to designing interventions. 1st ed. Great Britain: Silverback Publishing; 2014. p. 1003-10.

\section{Publisher's Note}

Springer Nature remains neutral with regard to jurisdictional claims in published maps and institutional affiliations.
Ready to submit your research? Choose BMC and benefit from:

- fast, convenient online submission

- thorough peer review by experienced researchers in your field

- rapid publication on acceptance

- support for research data, including large and complex data types

- gold Open Access which fosters wider collaboration and increased citations

- maximum visibility for your research: over 100M website views per year

At BMC, research is always in progress.

Learn more biomedcentral.com/submissions 